\title{
FAKTOR PENDUKUNG DAN PENGHAMBAT COLLABORATIVE GOVERNANCE DALAM PENGELOLAAN RUANG TERBUKA HIJAU DI KABUPATEN LUWU UTARA
}

\author{
Elya Septiani $^{1}$, Muhammadiah $^{2}$, Mappamiring $^{3}$ \\ Universitas Muhammadiyah Makassar \\ e-mail : elyaseptiani1995@gmail.com
}

\begin{abstract}
This study aims to determine the process of collaborative governance in managing green open spaces in North Luwu Regency. The research method used is a qualitative method with a phenomenological type. The data sources of this study were primary data sources obtained through interviews with informants, while secondary data were obtained from documents related to the research topic. The technique of determining informants using purposive technique. The results of the study found that the supporting factors in the collaboration process are: (a) social structure factors, the existence of a trusting relationship, mutual awareness of each of the duties and functions of each stakeholder in managing open space, b) government interests, that the government has an interest in managing the environment living by providing green open space, which is then described in the policy on green open space management regulated in Law Number 26 of 2007 concerning Spatial Planning. The factors inhibiting the collaboration process are cultural factors, that people around green open spaces have a habit or culture of breeding, where these livestock are allowed to roam so that they damage green open space facilities and the community still has a habit of assuming that the government is fully responsible green open space so that the role and participation of the community is still low.
\end{abstract}

Kata Kunci: Collaborative, Governance, Green Open Space

\begin{abstract}
Abstrak
Penelitian ini bertujuan untuk mengetahui proses collaborative governance dalam pengelolaan ruang terbuka hijau di Kabupaten Luwu Utara. Metode penelitian yang digunakan adalah metode kualitatif dengan tipe fenomenologi. Adapun sumber data dari penelitian ini yakni sumber dta primer yang diperoleh melalui interview dengan informan, sedangkan data sekunder diperoleh dari dokumen yang terkait dengan topic penelitian. Teknik penentuan informan menggunakan teknik purposive. Hasil penelitian menemukan bahwa faktor pendukung dalam proses kolaborasi yakni: (a) faktor struktur sosial, adanya hubungan saling percaya, saling menyadari akansetiap tugas dan fungsi masing-masing stakeholder dalam mengelola ruang terbuka, b) kepentingan pemerintah, bahwa pemerintah memiliki kepentingan dalam mengelola lingkungan hidup dengan menyediakan ruang terbuka hijau, yang kemudian kepentingan tersebut dijabarkan dalam kebijakan tentang pengelolaan ruang terbuka hijau diatur dalam UU Nomor 26 Tahun 2007 Tentang Penataan Ruang. Adapun fakto penghambat proses kolaborasi yakni faktor kultural, bahwa masyarakat disekitar ruang terbuka hijau memiliki kebiasaan atau budaya beternak, yang mana hewan ternak ini dibiarkan berkeliaran sehingga merusak fasilitas ruang terbuka hijau dan masyarakat pun masih memiliki kebiasaan yang menganggap bahwa pemerintah yang sepenuhnya yang bertanggung jawab terhadap ruang terbuka hijau sehingga peran dan partisipasi masyarakat masih rendah.
\end{abstract}

Kata Kunci : Collaborative, Governance, Ruang Terbuka Hijau

\section{PENDAHULUAN}

Bagian terpenting dalam pengelolaan lingkungan yang telah banyak diterapkan pemerintah di berbagai wilayah Indonesia baik tingkat provinsi maupun daerah adalah pengelolaan ruang terbuka hijau sebagai bentuk pembangunan yang berlandaskan lingkungan hidup. Seiring lajunya pembangunan dalam rangka mewujudkan pembangunan yang berwawasan lingkungan dan terdapat keinginan masyarakat dalam 
pemanfaatan ruang terbuka hijau. Dengan tujuan meningkatkan kualitas kehidupan maka diperlukan suatu agenda penataan untuk pengendalian dan pengawasan terhadap ruang terbuka hijau.

Salah satu produk hukum yang dibuat untuk mendukung terkelolanya lingkungan hidup adalah UU Nomor 26 Tahun 2007 Tentang Penataan Ruang, yang terdapat pada pasal 28 huruf a mengatur tentang penyediaan dan perencanaan ruang terbuka hijau yang selanjutnya diatur di dalam PERMEN PU NO 5/PRT/M/2008 tentang pedoman penyediaan ruang terbuka hijau di kawasan perkotaan. Kemudian untuk menyelaraskan PERMEN tersebut Kabupaten Luwu Utara membuat suatu produk normatif sebagai bentuk keturutsertaan dalam pengelolaan ruang terbuka hijau. Produk normatif tersebut dibuat dalam bentuk PERDA Kab. Luwu Utara Nomor 7 Tahun 2016 Tentang Pengelolaan Ruang Terbuka Hijau Bagian Wilayah Perkotaan Masamba.

Pembangunan ruang terbuka hijau di daerah perkotaan Masamba telah berlangsung kurang lebih 3 tahun semenjak diberlakukannya PERDA tersebut. Di Kabupaten Luwu Utara terdapat lima titik ruang terbuka hijau salah satunya ruang terbuka hijau Taman Sulikan. Dalam pengelolaan ruang terbuka hijau Taman Sulikan terlibat beberapa instansi pemerintahan yang berkolaborasi dan juga pihak swasta

Studi collaborative governance sangat relevan untuk digunakan dalam hal ini, dikarenakan pada umumnya istilah kolaborasi menggambarkan hubungan kerjasama yang dilakukan oleh berbagai pihak. Menggunakan konsep collaborative governance ini begitu bermanfaat untuk mengidentifikasi masalah pemerintahan sekaligus untuk menemukan alternatif dalam menyelesaikan permasalahan di pemerintahan. Diharapkan dengan konsep tersebut pihak yang berkolaborasi mampu memahami tugas serta fungsinya masingmasing sehingga terjalin koordinasi dalam mencapai tujuan dari kolaborasi tersebut.

Collaborative governance itu sendiri menurut Ansell dan Gash (2008) dalam Irawan, 2017, merupakan suatu pengaturan dalam pemerintahan yang di dalamnya terdapat satu atau lebih lembaga publik yang secara langsung melibatkan para pemangku kepentingan dalam proses pengambilan keputusan kolektif yang bersifat formal, berorientasi pada konsesus, deliberatif yang bertujuan untuk membuat dan menerapkan kebijakan publik serta mengelola program publik. Hal ini menjelaskan bahwa dalam collaborative governance melibatkan stakeholder dalam mencapai tujuan dari kolaborasi tersebut.

Berdasarkan PERMEN PU NO 5/PRT/M/2008 tentang pedoman penyediaan ruang terbuka hijau di kawasan perkotaan, diterangkan bahwa proporsi ataupun kebutuhan ruang terbuka hijau di kawasan perkotaan minimal $30 \%$ yang terdiri dari $20 \%$ ruang terbuka hijau publik dan $10 \%$ ruang terbuka hijau privat. Sehingga pemerintah Kabupaten Luwu Utara pun harus memenuhi proporsi tersebut. Namun fakta di lapangan, dalam perjalanannya telah banyak tamantaman ruang terbuka hijau yang mengalami kerusakan dan tidak terawat lagi. Hal ini dapat dilihat dari beberapa fasilitas-fasilitas taman ruang terbuka hijau yang telah rusak dan sudah tidak layak lagi digunakan, tanamantanaman yang tidak terawat yang dibiarkan rimbun dan petugas keamanan yang sangat jarang ada di pos keamanan taman. Hal ini menunjukkan bahwa tugas dan fungsi perangkat daerah dalam pemeliharaan ruang terbuka hijau masih belum berjalan secara baik dan maksimal. Maka perlu dilakukan penelitian mendalam untuk mengetahui faktor pendukung dan penghambat rung terbuka hijau, dengan merujuk pada (a) faktor struktur sosial merupakan salah satu faktor yang dapat mempengaruhi jalannya collaborative governance. Sebagaimana yang telah didiskusikan oleh Campbell (dalam Sepriandi, 2019) bahwa modal struktur sosial mengacu pada hubungan di antara orang-orang (jaringan sosial mereka) dan norma timbal balik, serta kepercayaan yang muncul dari mereka. Hambatan lainnya bagi kolaborasi dalam struktur yang vertikal tersebut adalah kekakuan yang terjadi pada bagian timbulnya kesenjangan pendapat pada pemerintah, (b) Faktor kultural berkaitan erat dengan budaya kerja yang dilakukan oleh sumber daya manusia yang terlibat dalam kolaborasi. Kaner (dalam Supriandi, 2019) bahwa pelaksana, pemimpin dan fasilitator harus mencontohkan komitmen untuk belajar dan mengadopsi keterampilan kolaboratif seperti 
mendengarkan aktif, memastikan bahwa semua peserta didengarkan dan diperlakukan secara adil, mengidentifikasi dan menguji asumsi, berperilaku dan berkomunikasi secara otentik dan sabar menggerakkan kelompok dengan kecepatan yang memastikan semua termasuk dan (c) Faktor terakhir adalah faktor kepentingan pemerintah yang erat kaitannya dengan faktor politik kepentingan diantara para pemangku kepentingan. Sebagaimana yang dijelaskan Sudarmo (2011) bahwa perubahan kesepakatan yang telah disetujui diawal kesepakatan kerjasama akibat adanya kepentingan baru yang berbeda-beda dari masing-masing pemangku kepentingan dapat menghambat proses kolaborasi tersebut.

\section{METODE}

Metode penelitian yang digunakan adalah metode kualitatif dengan tipe fenomenologi. Adapun sumber data dari penelitian ini yakni sumber data primer yang diperoleh melalui interview dengan informan, sedangkan data sekunder diperoleh dari dokumen yang terkait dengan topic penelitian. Pengumpulan data dilakukan melalui observasi, wawancara dan dokumentsi. Teknik penentuan informan menggunakan teknik purposive.

\section{HASIL DAN PEMBAHASAN}

Dari hasil penelitian dan analisis maka faktor pendukung proses collaborative governance dalam pengelolaan ruang terbuka hijau yakni :

\section{a. Struktur Sosial}

Faktor struktur sosial menjadi salah satu yang mempengaruhi proses kolaborasi. Pada struktur sosial terpacu hubungan antar stakeholder dalam proses kolaborasi. Struktur sosial ini sendiri berkaitan tentang struktuk perencanaan, struktur tugas dan fungsi stakeholder sehingga menjelaskan hubungan kolborasi. Setiap stakeholder telah mengetahui akan tugas dan fungsinya dalam proses kolaborasi pengelolaan ruang terbuka hijau. Maka dengan begitu akan menumbuhkan sikap kesadaran stakeholder terhadap tugasnya. Membangun sikap sadar akan tugasnya meningkatkan kinerja dalam proses kolaborasi tidak hanya sekedar melaksanakan tugas tetapi juga memperhatikan hasil maksimal dalam pekerjaannya.

b. Kepentingan Pemerintah

Faktor kepentingan pemerintah sangat berkaitan dengan kepentingan politik antar stakeholder yang berkolaborasi. Salah satu bentuk kepentingan pemerintah ialah dengan adanya pembuatan kebijakan. Salah satu bentuk kepentingan pemerintah berkaitan dengan lingkungan hidup yakni adanya kebijakan mengenai pengelolaan ruang terbuka hijau.

Kebijakan tentang pengelolaan ruang terbuka hijau diatur dalam UU Nomor 26 Tahun 2007 Tentang Penataan Ruang, pada pasal 28 huruf a mengatur tentang penyediaan dan perencanaan ruang terbuka hijau yang kemudian diatur dalam PERMEN PU No 5/PRT/M/2008 tentang pedoman penyediaan ruang terbuka hijau di kawasan perkotaan kemudian oleh pemerintah Kabupaten Luwu Utara dibuatlah Perda Kabupaten Luwu Utara No.7 Tahun 2016 tentang Pengelolaan Ruang Terbuka Hijau Bagian Wilayah Perkotaan Masamba.

Kebijakan yang berkaitan dengan pengelolaan ruang terbuka hijau sudah seharusnya menjadi faktor pendukung. Dengan adanya kebijakan tersebut mampu mengatur dan mengarahkan suatu program berjalan baik.

Adanya kebijakan tersebut, diharapkan semakin menumbuhkan kepedulian dalam melestarikan dan meningkatkan kualitas lingkungan hidup melalui penyediaan ruang terbuka hijau. Sehinga salah astu yang dapat menjadi faktor pendukung terkelolanya ruang terbuka hijau ialah kebijakan yang mengatur tentang ruang terbuka hijau.

Kemudian adapun yang menjadi faktor penghambat proses kolaborasi dalam pengelolaan ruang terbuka hijau, yakni :

\section{Faktor Kultural}

Pada faktor ini sangat berkaitan dengan budaya yang dilakukan dalam kolaborasi. Dari hasil penelitian masyarakat yang berada disekitar ruang terbuka hijau memiliki budaya atau kebiasaan bertenak hewan, misalnya hewan kerbau. Kebiasaan memelihara hewan ternak menjadi masalah nyata yang dihadapi dalam proses kolaborasi ruang terbuka hijau. 
Yang mana hewan ternak ini masih sulit untuk ditertibkan. Berbagai upaya pun telah dilakukan untuk mengatasi hewan ternak termasuk dengan memberi surat peringatan dan denda, namun tetap saja hewan ternaknya berkeliaran bebas disekitar ruang terbuka hijau taman dan merusak fasilitas taman dan tanaman yang ada di ruang terbuka hijau.

Faktor kultural lainnya adalah kebiasaan atau budaya pemahaman masyarakat yang menganggap bahwa hanya pemerintah yang memiliki peran dan tanggung jawab terhadap pengelolaan ruang terbuka hijau. Dalam proses kolaborasi peran serta masyarakat diperlukan, hal ini yang membuat kurangnya peran masyarakat dan masih rendahnya partisipasi masyarakat dalam pengelolaan ruang terbuka hijau.

Berdasarkan Permen PU No 5/PRT/M/2008 tentang pedoman penyediaan ruang terbuka hijau di kawasan perkotaan bahwa masyarakat dapat berperan secara individual atau kelompok dalam penyediaan dan pemanfaatan ruang terbuka hijau.

Namun dari hasil penelitian di lapangan menunjukkan masyarakat di sekitar ruang terbuka hijau banyak yang membuang sampahnya disembarang tempat di sekitar ruang terbuka hijau. Fasilitas yang ada di ruang terbuka hijau digunakan untuk menjemur.

Hal tersebut menunjukkan bahwa kesadaran masyarakat masih lemah untuk turut berpartisipasi dalam mengelola dan memelihara ruang terbuka hijau. Sekalipun respon masyarakat terhadap ruang terbuka hijau baik namun masih diperlukan usaha untuk mampu meningkatkan kesadaran dan pertisipasi masyarakat dalam mengelola ruang terbuka hijau sebagai wujud dari pembangunan lingkungan hidup.

\section{KESIMPULAN}

Berdasarkan hasil observasi, wawancara dan analisis maka kesimpulan dari faktor pendukung proses kolaborasi dalam pengelolaan ruang terbuka yakni : (a) faktor struktur sosial, adanya hubungan saling percaya, saling menyadari akansetiap tugas dan fungsi masing-masing stakeholder dalam mengelola ruang terbuka, b) kepentingan pemerintah, bahwa pemerintah memiliki kepentingan dalam mengelola lingkungan hidup dengan menyediakan ruang terbuka hijau, yang kemudian kepentingan tersebut dijabarkan dalam kebijakan tentang pengelolaan ruang terbuka hijau diatur dalam UU Nomor 26 Tahun 2007 Tentang Penataan Ruang. Adapun faktor penghambat proses kolaborasi yakni faktor kultural, bahwa masyarakat disekitar ruang terbuka hijau memiliki kebiasaan atau budaya beternak, yang mana hewan ternak ini dibiarkan berkeliaran sehingga merusak fasilitas ruang terbuka hijau dan masyarakat pun masih memiliki kebiasaan yang menganggap bahwa pemerintah yang sepenuhnya yang bertanggung jawab terhadap ruang terbuka hijau sehingga peran dan partisipasi masyarakat masih rendah.

\section{DAFTAR PUSTAKA}

Abdurrahim, A.Y, 2015. Skema Hutan Kemasyarakatan (HKM) Kolaboratif Sebagai Solusi Penyelesaian Konflik Pengelolaan SDADI Hutan Sesaot Lombok Barat. Jurnal Sosiologi Pedesaan Vol 3 No 3

Arianti, Iin, 2010. Ruang Terbuka Hijau. Jurnal Ilmu Pengetahuan dan Rekayasa Vol 3 No 1

Arifiyanti, H N, 2014. Analisis Ruang Terbuka Hijau Kota Semarang Dengan Menggunakan Sistem Informasi Geografis. Jurnal GeodsiUndip Vol 3 No 1

Batara, AS, 2018. Pentingnya Kolaborasi Stakeholder Dalam Mewujudkan Terminal Sehat di Sulawesi Selatan. The Indonesian Journal Of Health Promotion Vol 1 No 1

Emerson K, Nabatchi T, Balogh S, 2011. An Integrative Framework For Collaborative Governance. Journal of Public Administration Reseach and Theory 22:1-29

Falah, Faiqotul, 2013. Kajian Efektivitas Pengelolaan Kolaboratif Taman Nasional Kutai. Jurnal Analis Kebijakan Kehutanan Vol.10 No. 1 
Farida, K M, 2010. Prospek dan Permasalahan Pengembangan Ruang Terbuka Hijau Sebagai Pengurangan Dampak dan Adaptasi Terhadap Pemanasan Lokal. Jurnal Arsitektur dan Perencanaan Vol.4 No.2

Haryono, Nanang, 2012. Jejaring Untuk Membangun Kolaborasi Sektor Publik. Jurnal Jejaring Administrasi Publik Vol 4 No 1

Hidayatulloh dan Hutami, 2019. Collaborative governance in Gender Mainstreaming Policy in Yogyakarta City. Jurnal Studi Pemerintahan Vol 10 No 2

Imansari, Nadia, 2015. Penyediaan Hutan Kota dan Taman Kota Sebagai Ruang Terbuka Hijau (RTH) Publik Menurut Preferensi Masyarakat di Kawasan Pusat Kota Tangerang. Jurnal Ruang Vol 1 No 3

Innes, J.E. dan Booher, D.E. (2010). Beyond Collaboration Democratic Governance for a Resilient Society in Planning with Complex-ity, An Introduction to collaborative rationality or public policy, pp 196-215., Routledge, Oxon.

Irawan, Denny, 2017. Collaborative Governance (Studi Deskriptif Proses Pemerintahan Kolaboratif Dalam Pengendalian Pencemaran Udara di Kota Surabaya). Jurnal Kebijakan dan Manajemen Publik Vol 5 No3

Jovi, A k dan Retno, S, 2017. Sinergitas Antar Stakeholders dalam Pengelolaan Ruang Terbuka Hijau (RTH) Taman Kota di Kota Temanggung. Jurnal Wacana Publik Vol 1 No 1

Kim, Soonhee, 2009. Management Strategy for Local Government, Seoul, United Nations Project Office On Governance

Lukito, 2016. Collaborative Governance Dalam Pengembangan Kerajinan Blangkon di Kecamatan Serengan Kota Surakarta. JIAP Vol 3 No 1

Marmi, 2016. Ruang Terbuka Hijau (RTH) Kota Surabaya Sebagai Wahana
Peningkatan Kemampuan Dasar Sistematik Tumbuhan. Jurnal Inovasi Vol XVIII No. 1

Marta, Auradian, 2016. Pengelolaan Daerah Aliran Sungai Terpadu di Provinsi Riau dalam Perspektif Collaborative Governance. Prosiding Seminar Nasional Reformasi dan Inovasi Tata Kelola Pemerintahan

Muhammad, dkk, 2017. Collaborative Governance Model in Managing International Borders in Riau Island Province Using Partial Least Squares Method. Jurnal Kebijakan dan Administrasi Publik Vol. 21 No. 2

Mustari, Nuryanti, 2013. Implementasi Kebijakan Publik Pemahaman Teoritis Empiris. Makassar : Membumi Publishing

Novita, A A, 2018. Collaborative Governance dan Pengelolaan Lingkungan Hidup di Kawasan Pertambangan. Jurnal Ilmu Administrasi Publik Vol 4 Nol

Nurlina, S dan Risma, H, 2017. Partisipasi Masyarakat Perkotaan dalam Pengelolaan Ruang Terbuka Hijau Sebagai Urban, Makassar, Indonesia. Prosiding Seminar Hasil Penelitian (SNP2M) pp 131-135

O'leary, Resemary, et all,2010. The Future Of Public Administration Around The World,Washinton Dc ; Georgetown University Press Penelitian. Jogjakarta: Ar-Ruzz Media.

Prastowo, Andi. 2011. Metode Penelitian Kualitatif dalam Perspektif Rancangan

Purdy, JM, 2012. A Framework For Assessing Power in Collaborative Governance Proceses. Journal of Public Administration Review vol 72 iss 3

Rawung, F C, 2015. Efektivitas Ruang Terbuka Hijau (RTH) Dalam Mereduksi Emesi Gas Rumah Kaca (GRK) di Kawasan Perkotaan Boroko. Jurnal Media Matrasain Vol 12 No 2 
Rijal, Syamsu, 2008. Kebutuhan RTH di Kota Makassar Tahun 2017. Jurnal Hutan \& Masyarakat Vol III No.1

Sepriandi, Sigit, 2019. Faktor-faktor Yang Mempengaruhi Collaborative Governance. Jurnal Ilmu Pemerintahan dan Social Politik MUA Vol 7 No 1

Sudarmo, 2011. Isu-Isu Administrasi Publik Dalam Perspektif Governance. Surakarta : Smart Media

Sufianti, Ely dkk, 2012. Proses Kolaboratif Dalam Perencanaan Berbasis Komunikasi Pada Masyarakat Non Kolaboratif. Jurnal Mimbar Vol 29 No 2

Sufianti, Ely, 2014. Kepemimpinan dan Perencanaan Kolaboratif Pada Masyarakat Non-Kolaboratif. Jurnal Perencanaan Wilayah dan Kota Vol 25 No 1 